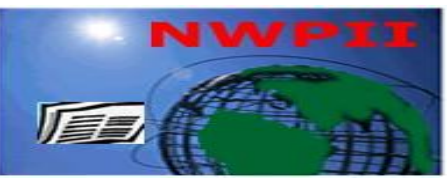

American Journal of Biomedical Sciences

ISSN: 1937-9080

nwpii.com/ajbms

\title{
Antioxidant and Anti-inflammatory Effects of Curcumin on CCl4 - induced Liver Fibrosis in Rats
}

\author{
Naglaa Fathi Khedr *, Eman Gouda Khedr
}

Department of Biochemistry, Faculty of Pharmacy, Tanta University, Egypt

*Corresponding author:

Naglaa F. Khedr

Department of Biochemistry

Faculty of Pharmacy

Tanta University

Tanta, Postal number: 31527

Egypt

Tel:+20403336007/158

Fax:+20403335466

E-mail: naglaa_khedr2000@yahoo.com

Received: 28 August 2014; | Revised:29 September 2014; | Accepted: 14 October 2014

\begin{abstract}
Background: Liver fibrogenesis can lead to the development of cirrhosis and hepatocellular carcinoma. This study was designed to evaluate the hepatoprotective effect of curcumin on $\mathrm{CCl}_{4}$-induced fibrosis in rats and to assess its antioxidant and anti-inflammatory properties. Method: Rats were divided into four groups. Group $1(\mathrm{n}=10)$ was control vehicle, Group $2(\mathrm{n}=10)$; rats were injected with $\mathrm{CCl}_{4}(1 \mathrm{~mL} / \mathrm{Kg}$ of $1: 1 \mathrm{v} / \mathrm{v}$ i.p. twice weekly for 12 week). Group 3 ( $\mathrm{n}=10)$; rats were injected with similar doses of $\mathrm{CCl}_{4}$ and given oral curcumin $(300 \mathrm{mg} / \mathrm{kg})$ for 4 weeks after withdrawal of $\mathrm{CCl}_{4}$. Group $4(\mathrm{n}=10)$; rats were injected with similar doses of $\mathrm{CCl}_{4}$ and given curcumin orally $\left(300 \mathrm{mg} / \mathrm{kg}\right.$ ) on the $6^{\text {th }}$ week of $\mathrm{CCl}_{4}$ treatment simultaneously for 6 weeks. Fibrosis was assessed histologically and by measuring liver hydroxyproline content. $\alpha$-smooth muscle actin was detected immunohistochemically. Serum markers of liver damage and oxidative stress were quantified. TGF- $\beta 1$ expression in liver was determined by RT-PCR and quantified in plasma. Results: $\mathrm{CCl}_{4}$ resulted in elevation of ALT, AST, total bilirubin, TGF- $\beta 1$ and liver hydroxyproline $(\mathrm{P}<0.05)$, whereas plasma total protein, glutathione peroxidase and superoxide dismutase activities were reduced $(\mathrm{P}<0.05)$. The histopathological changes were apparently ameliorated in the curcumin treated rats. Curcumin suppressed liver fibrosis indices and TGF- $\beta 1$ expression in hepatocytes following $\mathrm{CCl}_{4}$ injections $(\mathrm{P}<0.001)$. Curcumin enhanced liver antioxidant enzyme activities $(\mathrm{P}<0.001)$. Conclusion: These findings suggested that the antioxidant and anti-inflammatory effects of oral curcumin on hepatic fibrogenesis might be considered as its mechanisms to improve hepatic fibrogenesis.
\end{abstract}

Keywords: Fibrogenesis, $\mathrm{CCl}_{4}$, Curcumin, TGF- $\beta 1$, Hydroxyproline. 


\section{Introduction}

Currently, there are hundreds of million patients with liver fibrosis throughout the world, and most cases are caused by hepatitis viral infections. Hepatic fibrosis is a progressive pathological process involving multiple cellular and molecular events. It is a result of an imbalance between enhanced extracellular matrix protein (ECM) synthesis and diminished breakdown of connective tissue proteins. Hepatic stellate cells (HSCs) are the primary effector cells in liver fibrosis orchestrating the deposition of ECM in normal and fibrotic liver. Cytokinemediated activation of HSCs into a myofibroblast-like phenotype is a key event during liver fibrogenesis [1].

Oxidative stress plays an important role in initiation of fibrogenesis by increasing harmful cytokines, in particular the most profibrogenic cytokine, transforming growth factor- $\beta$ (TGF- $\beta$ ). Therefore, antioxidants are useful as anti-liver fibrosis therapy. They are targeting the cause of liver fibrosis and delaying or interrupting the pathological progression [2].

Carbon tetrachloride $\left(\mathrm{CCl}_{4}\right)$ is widely used for experimental induction of liver damage. Chronic liver damage induced by $\mathrm{CCl} 4$ in rats produces liver fibrosis and biochemical and histological patterns that resemble human liver cirrhosis. $\mathrm{CCl}_{4}$ induced hepatic damage in lipid peroxidation and decreased activities of antioxidant enzymes and generation of free radicals [3].

Various medicinal plants have been used to treat for various diseases in all over the world. Nowadays, Indian medicinal plants were investigated as liver protective drugs. Curcumin is a bioactive food component present in the golden spice Curcuma longa. It is an essential component of curry powder. Curcumin modulates the biological activity of many signaling molecules. It has anti-cancer activities that have been demonstrated in many studies which attributed to its antioxidant and anti-inflammatory properties [3].

Therefore, we aimed in this study to evaluate the ability of curcumin to prevent the development and progression of $\mathrm{CCl}_{4}$-induced liver fibrosis in rats during $\mathrm{CCl}_{4}$ administration and to investigate its molecular mechanisms underlying these effects.

\section{Materials and Methods}

\subsection{Chemicals}

Curcumin, Folin and Ciocalteu's Phenol Reagent $(2 \mathrm{~N})$, chloramine-T, Ehrlich reagent, carboxymethylcellulose and $\mathrm{CCl}_{4}$ were purchased from Sigma Aldrich (USA).

\subsection{Animals and Experimental Protocols}

The study was performed in accordance with the guidelines for the care and use of laboratory animals approved by Research Ethical Committee (Faculty of pharmacy, Tanta University, Egypt). Male Wistar rats weighing 120-150 g (12 week-old) were obtained from National Research Center (Egypt) and maintained in wire cages for 1 week for acclimatization with free access to food and water. Liver fibrogenesis was induced by administration of $1 \mathrm{~mL}$ of $\mathrm{CCl}_{4} /$ corn oil $(1: 1, \mathrm{v} / \mathrm{v}) / \mathrm{kg}$ body weight i.p. injection twice weekly for 12 weeks [4]. Rats were randomly divided into four groups.

Group (1): Control vehicle $(\mathrm{n}=10)$; rats were received $1 \mathrm{~mL}$ i.p. injection of corn oil twice weekly and $1 \mathrm{~mL}$ of $0.7 \%$ carboxymethylcellulose orally, three times/week.

(CMC)

Group (2): $\mathrm{CCl}_{4}(\mathrm{n}=10)$; rats were injected with $1 \mathrm{~mL}$ of $\mathrm{CCl}_{4} /$ corn oil $(1: 1, \mathrm{v} / \mathrm{v}) / \mathrm{kg}$, i.p. injection twice weekly for 12 weeks.

Group (3): $\mathrm{CCl}_{4}+$ curcumin $4 \mathrm{w}(\mathrm{n}=10)$; rats were injected with similar doses of $\mathrm{CCl}_{4}$ for 12 weeks and given oral curcumin suspended in $0.7 \% \mathrm{CMC}$ (300 mg/kg, three times/week) for four weeks after withdrawal of $\mathrm{CCl}_{4}$.

Group (4): $\mathrm{CCl}_{4}+$ curcumin $6 \mathrm{w}(\mathrm{n}=10)$; rats were injected with similar doses of $\mathrm{CCl}_{4}$ and co-treated with similar doses of curcumin after 6 weeks of $\mathrm{CCl}_{4}$ treatment for successive 6 week.

At the end of experiment rats were killed under light ether anesthesia; blood samples were collected via cardiac puncture. Plasma were 
collected and stored at $-20^{\circ} \mathrm{C}$ for further analyses. Small portions of the liver were removed for immunohistochemical and histopathological studies. The remaining liver tissue was cut into pieces and rapidly frozen in liquid nitrogen ($80^{\circ} \mathrm{C}$ ) for extraction of total RNA and for determination of hepatic antioxidant enzyme activities and liver hydroxyproline content.

\subsection{Liver function tests}

Liver marker enzymes such as alanine aminotransferase (ALT), aspartate aminotransferase (AST) activities were measured in plasma for determining liver damage and total bilirubin using commercial kits (Biodiagnostic Co, Egypt). Plasma level of TGF- $\beta 1$ of rats was determined by using ELISA kit purchased from eBiosciences (Vienna, Austria) according to the protocol provided by the manufacturer. Plasma total protein was measured by Folin`s reaction according to Lowry et al [5].

\subsection{Collagen quantification (Measurement of hepatic hydroxyproline content)}

Collagen concentration was determined by measuring hepatic hydroxyproline content. It was performed using a colorimetric method described by Bergman and Loxley [6]. The absorbance was read at $558 \mathrm{~nm}$ using Unicam spectrophotometer (USA). Trans-hydroxyproline was used as the standard for quantification. Results were expressed as $\mathrm{mmoL}$ hydroxyproline per gram of hepatic tissue.

\subsection{Glutathione peroxidase (GPx) activity (GP, EC 1.11.1.9)}

Liver tissue was homogenized in 4-8 volumes (per weight tissue) of cold buffer (50 $\mathrm{mM}$ phosphate buffer, $\mathrm{pH} 7.0$ containing $5 \mathrm{mM}$ EDTA and $1 \mathrm{mM}$ dithiothreitol). The homogenate was centrifuged at $700 \mathrm{~g}$ for $15 \mathrm{~min}$ at $2-8^{\circ} \mathrm{C}$. The supernatant fluid containing the enzyme was collected. GPx activity was measured indirectly [7] using a commercial kit (Biodiagnostic Co., Giza, Egypt).

\subsection{Superoxide Dismutase Activity (SOD, EC 1.15.1.1):}

Liver tissue was perfused with PBS $(\mathrm{pH}$ 7.4) containing $0.16 \mathrm{mg} / \mathrm{mL}$ heparin to remove any RBCs. $0.1 \mathrm{~g}$ tissue was homogenized in 5-10 $\mathrm{mL}$ cold buffer (100 $\mathrm{mM}$ potassium phosphate, $\mathrm{pH} 7.0$, containing $2 \mathrm{mM}$ EDTA) per gram tissue. Liver homogenate was centrifuged at $700 \mathrm{~g}$ for $15 \mathrm{~min}$ at $4^{\circ} \mathrm{C}$. The supernatant was collected and stored at $-20^{\circ} \mathrm{C}$ until assay. SOD activity [8] was determined using a commercial kit (Biodiagnostics, Giza, Egypt).

\subsection{RNA extraction and RT-PCR}

Total RNA was extracted from rat hepatic tissue using SV Total RNA isolation kit (Promega, Madison, WI, USA). RNA concentrations and purity were determined by measuring the absorbance A260 nm/A280 nm ratio using Nanodrop 2000 spectrophotometer (Thermo Fisher Scientific Inc., USA). Reverse transcriptase-PCR was carried out with the extracted total RNA as a template using kit (Qiagen One Step RT-PCR, USA). The following primers were used for TGF- $\beta 1$ : 5'TGGACCGCAACAACGCCATCTATGAGAA AACC-3 (forward) and 5'TGGAGCTGAAGCAATAGTTGGTATCCAGG GCT- 3 (reverse) and $\beta$-actin as control gene; 5 GGAGAAGATGACCCAGATCA-3` (forward), 5-GATCTTCATGAGGTAGTCAG-3'(reverse)

[9]. Reactions were performed as follows: an initial step at $94{ }^{\circ} \mathrm{C}$ for $1 \mathrm{~min} 30 \mathrm{~s}$, followed by 35 cycles $\left(1 \mathrm{~min}\right.$ at $94{ }^{\circ} \mathrm{C}, 1 \mathrm{~min}$ at $64^{\circ} \mathrm{C}$ and $1 \mathrm{~min}$ at $72{ }^{\circ} \mathrm{C}$ ) and finally a 3 min extension step at 72 ${ }^{\circ} \mathrm{C}$. After PCR, products were electrophoresed on agarose gels, stained with ethidium bromide, and images were recorded using Gel Doc XR system (Bio-Rad Inc. USA).

\subsection{Liver Histopathology}

Small portions of liver tissues were fixed in $10 \%$ neutral buffered formalin, embedding the specimens in paraffin, making $5 \mathrm{~mm}$ thick sections and staining the sections with hematoxylin (H) \& eosin (E) [10]. The pathological grading was based on the criteria of Histological Grading and Staging of Chronic Hepatitis [10]. S0 stage, no fibrosis; S1 stage, expansion of fibrosis in portal area, localized perisinusoidal and intralobular fibrosis; S2 stage, 
peripheral fibrosis in portal area, formation of fibrous septum, retention of intralobular architecture; S3 stage, fibrous septum accompanied by intralobular structural disorders, no hepatic cirrhosis; S4 stage, early hepatic cirrhosis [10]. Liver fibrosis was observed under light microscopy.

\subsection{Immunohistochemical studies of alpha- smooth muscle actin ( $\alpha-S M A)$}

Mouse monoclonal antibodies against $\alpha$ SMA were used at a dilution of 1:800 (clone 1A4, Sigma Co., St. Lois, MO, USA). After three washes with PBS, sections were incubated with goat anti-rabbit secondary antibodies (Invitrogen, Carlsbad, CA) for $1 \mathrm{~h}$. Sections incubated with secondary antibodies alone were used as negative controls [11].

\section{Statistical Analysis:}

All data are expressed as the mean \pm SD. The SPSS 16.0 software [12] was used for statistical analysis. Student's $t$-test was used for the comparison between the means of two samples. ANOVA was applied for the comparison among the means of multiple samples.

\section{Results}

\subsection{Effect of curcumin on indices of hepatic fibrosis}

Marker of liver damage (ALT, AST, total bilirubin) were increased and plasma total protein was decreased significantly $(\mathrm{P}<0.001)$ by chronic $\mathrm{CCl}_{4}$ administration when compared with control vehicle group (Table 1). Treatment with curcumin prevented the increases of these markers and restored them to their normal levels $(\mathrm{P}<0.001)$. Plasma total protein level was also increased by curcumin administration compared to $\mathrm{CCl}_{4}$ treated group. The increase in plasma ALT and AST were completely prevented by curcumin after withdrawal of $\mathrm{CCl}_{4}$.

Table1: Effect of curcumin on liver function tests and antioxidant enzymes

\begin{tabular}{|c|c|c|c|c|}
\hline Parameters & Group (1) & Group (2) & Group (3) & Group (4) \\
\hline Total protein $(\mathrm{g} / \mathrm{dL})$ & $6.16 \pm 0.47$ & $5.10^{* * a} \pm 0.25$ & $6.8^{*} \pm 0.14$ & $5.27 \pm 0.13$ \\
\hline Total bilirubin (mg/dL) & $0.25 \pm 0.05$ & $0.65^{* * * 3 \times a} \pm 0.15$ & $0.35^{* * m} \pm 0.06$ & $0.3^{* * * * * \mathbf{b c}} \pm 0.04$ \\
\hline $\operatorname{ALT}(\mathbf{U} / \mathbf{L})$ & $35.30 \pm 6.22$ & $101.07^{* * * *} \mathrm{a} \pm 37.1$ & $24.36^{* * * * b} \pm 6.70$ & $24.86^{* * * * *} \mathbf{b c} \pm 6.85$ \\
\hline $\operatorname{AST}(\mathbf{U} / \mathbf{L})$ & $43.20 \pm 5.02$ & $72.3^{* * w^{*} \mathrm{a}} \pm 18.2$ & $16.16^{* * w^{*} \mathrm{~m}} \pm 4.55$ & $48.42^{* * * \cdots b c} \pm 8.6$ \\
\hline $\begin{array}{c}\text { Hydroxyprolin (mmol/g } \\
\text { tissue) }\end{array}$ & $1.73 \pm 0.18$ & $6.12^{* * * * a} \pm 1.19$ & $2.11^{* * * * 6} \pm 0.45$ & $4.08^{* \mathbf{b c}_{ \pm}} \pm 0.05$ \\
\hline Serum TGF-B1 (pg/L) & $86.00 \pm 12.4$ & $191.0^{* * * * a} \pm 15.58$ & $91.02^{*, * 3 \times 6} \pm 12.86$ & $160.96^{* w^{*}} \pm 28.8$ \\
\hline $\begin{array}{c}\text { Liver Glutathione peroxidase } \\
\text { (GPx) (U/g tissue) }\end{array}$ & $21.4 \pm 4.73$ & $8.1^{6 * 2 \mathrm{a}} \pm 1.73$ & $24.27^{2 * 2 \times 6} \pm 5.2$ & 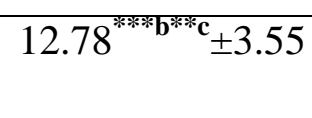 \\
\hline $\begin{array}{c}\text { Liver Superoxide dismutase } \\
\text { (SOD) }(\mathrm{U} / \mathrm{mL})\end{array}$ & $130.65 \pm 12.43$ & $51.5^{* * * * a} \pm 13.6$ & $206.52^{* * * *} \mathbf{b} \pm 58.5$ & $173.3^{* * * * 6 * *} \mathbf{c} \pm 7.78$ \\
\hline
\end{tabular}

Data are presented as mean \pm SD. $\mathrm{P}<0.05$ was set as significant. ${ }^{\mathbf{a}}$ : significant versus control vehicle. ${ }^{\mathbf{b}}$ : significant versus $\mathrm{CCL}_{4}$ Group (2). C: significant versus $\mathrm{CCl} 4+\mathrm{Cur} 4 \mathrm{w}$ Group (3). *: $\mathrm{P}<0.05$, **: $\mathrm{P}<0.02$, ***: $\mathrm{P}<0.001$. Group (1): Control vehicle $(\mathrm{n}=10)$; rats were received $1 \mathrm{~mL}$ i.p. injection of corn oil twice weekly and $1 \mathrm{~mL}$ of $0.7 \%$ carboxymethylcellulose (CMC) orally, three times/week. Group (2): $\mathrm{CCl}_{4}(\mathrm{n}=10)$; rats were injected with $1 \mathrm{~mL}$ of $\mathrm{CCl}_{4} /$ corn oil $(1: 1, \mathrm{v} / \mathrm{v}) / \mathrm{kg}$, i.p. injection twice weekly for 12 weeks. Group (3): $\mathrm{CCl}_{4}+$ curcumin $4 \mathrm{w}(\mathrm{n}=10)$; rats were injected with similar doses of $\mathrm{CCl}_{4}$ for 12 weeks and given oral curcumin suspended in $0.7 \% \mathrm{CMC}(300 \mathrm{mg} / \mathrm{kg}$, three times/week) for four weeks after withdrawal of $\mathrm{CCl}_{4}$. Group (4): $\mathrm{CCl}_{4}+$ curcumin $6 \mathrm{w}(\mathrm{n}=10)$; rats were injected with similar doses of $\mathrm{CCl}_{4}$ and co-treated with similar doses of curcumin after 6 weeks of $\mathrm{CCl}_{4}$ treatment for successive 6 weeks. 


\subsection{Effect of curcumin on Liver hydroxyproline content}

Extracellular matrix accumulation was estimated by measuring hydroxyproline content in the liver. Liver hydroxyproline content was reduced after curcumin treatment which indicated partial recovery from fibrosis (Table 1). Liver hydroxyproline level in $\mathrm{CCl}_{4}$ group was
$6.12 \pm 1.19 \mathrm{mmoL} / \mathrm{g}$ liver compared with control vehicle and decreased to $2.11 \pm 0.45(\mathrm{P}<0.001)$ and $4.08 \pm 0.05 \quad(\mathrm{P}<0.05) \quad$ after $\quad$ curcumin administration. The hepatoprotective effect of curcumin in recovery from fibrosis was more observed after $\mathrm{CCl}_{4}$ withdrawal compared to other groups.
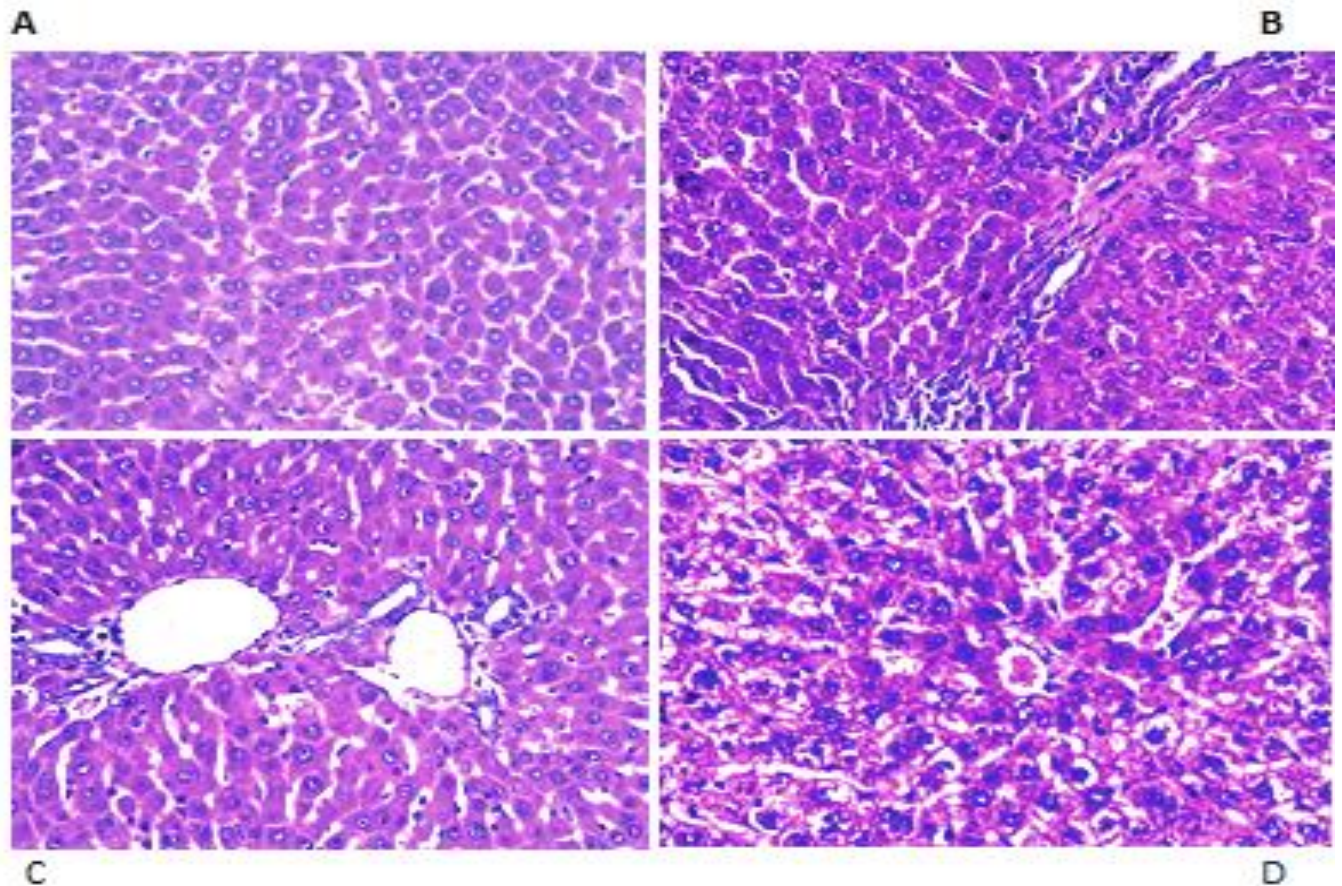

Figure 1: Photomicrographs of liver sections were stained with H-E stain $(\times 400)$. A: Group (1) control vehicle shows normal liver histology (Grade S0: no fibrosis). It shows radiating liver cords and normal hepatocytes. B: Group (2) $\left(\mathrm{CCl}_{4}\right.$ treated rats; $1 \mathrm{~mL}$ of CCl4/corn oil $(1: 1, \mathrm{v} / \mathrm{v}) / \mathrm{kg}$, i.p. injection twice weekly for 12 weeks) it shows Grade S3 of fibrosis(no hepatic cirrhosis); fibrosis is observed in the portal area with the formation of fibrous septum. Expanded portal tract with mononuclear cells and focal degenerated hepatocytes are observed. C: Group (3) (CCl4+curcumin 4w; $1 \mathrm{~mL}$ of $\mathrm{CCl} 4 /$ corn oil $(1: 1, \mathrm{v} / \mathrm{v}) / \mathrm{kg}$, i.p. injection twice weekly for 12 weeks $)+$ curcumin $(300 \mathrm{mg} / \mathrm{kg}$, three times/week) for 4 weeks after withdrawal of $\mathrm{CCl}_{4}$. It shows $\mathrm{S} 2$ grade (less degree of portal fibrosis), the fibrosis is localized in the lobules. D: Group (4) $\left(\mathrm{CCl}_{4}+\right.$ curcumin $6 \mathrm{w}(\mathrm{n}=10)$; rats were injected with similar doses of $\mathrm{CCl}_{4}$ and co-treated with similar doses of curcumin after 6 weeks of $\mathrm{CCl}_{4}$ treatment for successive 6 weeks). It shows $\mathrm{S} 2$ grade with early liver damage; hepatocytes show vacuolar degeneration and necrosis.

\subsection{Effect of curcumin on Liver Histopathology}

Histological examination of liver section in control group shows normal cellular architecture with radiating hepatic cords; normal sinusoidal spaces and central veins are present. While, sections of liver in $\mathrm{CCl}_{4}$ treated group (2) demonstrated necrosis in large area of liver tissue accompanied by neutrophil infiltration. Nonparenchymal cells were observed with activated myofibroblast-like hepatic stellate cells (HSCs) and clustered around the fibrotic septa. The liver specimens obtained from the rats treated with curcumin concomitant with $\mathrm{CCl}_{4}$ and after its withdrawal resulted in apparent amelioration of necrosis and inflammatory cellular infiltration in addition to a reduction of fibrous tissue with few number of HSCs, especially in liver tissue of group (3) (Figure 1). 


\subsection{Effect of curcumin on liver tissue immunostained with $\alpha$-SMA}

Immunostaining of $\alpha$-SMA was used to detect and quantify liver fibrosis. Liver sections of control group showed few HSC, suggesting that the latter were in their quiescent state. Chronic administration of $\mathrm{CCl}_{4}$ for 12 weeks resulted in marked increase in ECM content and displayed bundles of collagen surrounding the lobules, which resulted in fibrous septa. These septa were surrounded by $\alpha$-SMA positive cells which are characteristic of advanced fibrosis. Treatment with curcumin prevented the activation of most of the HSC and only traces of $\alpha$-SMApositive cells were detected (Figure 2).
A
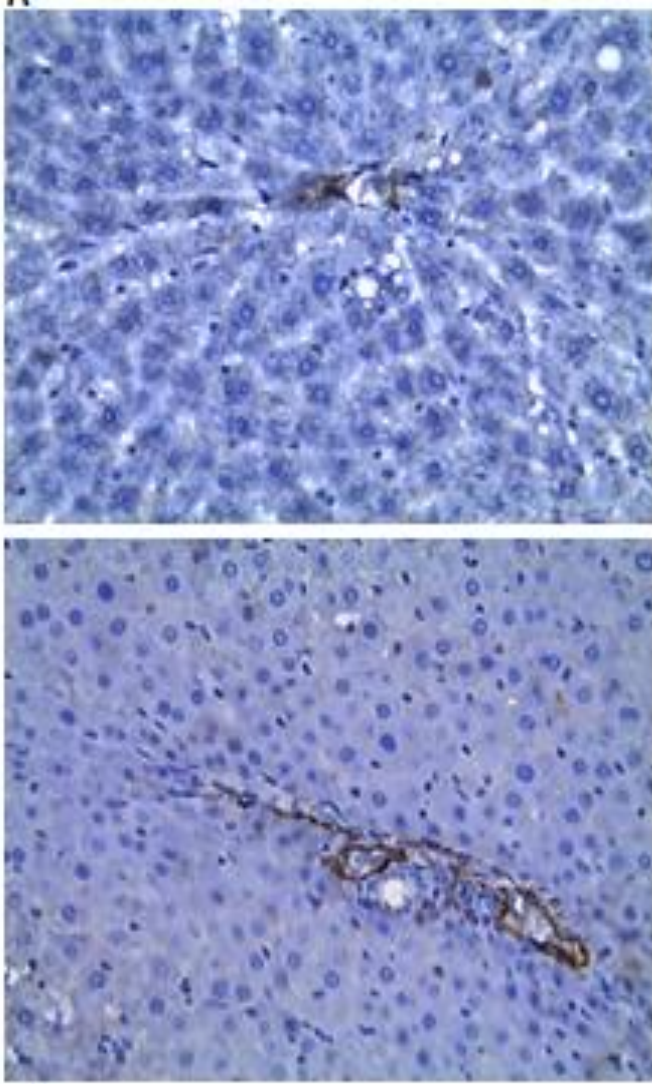

C
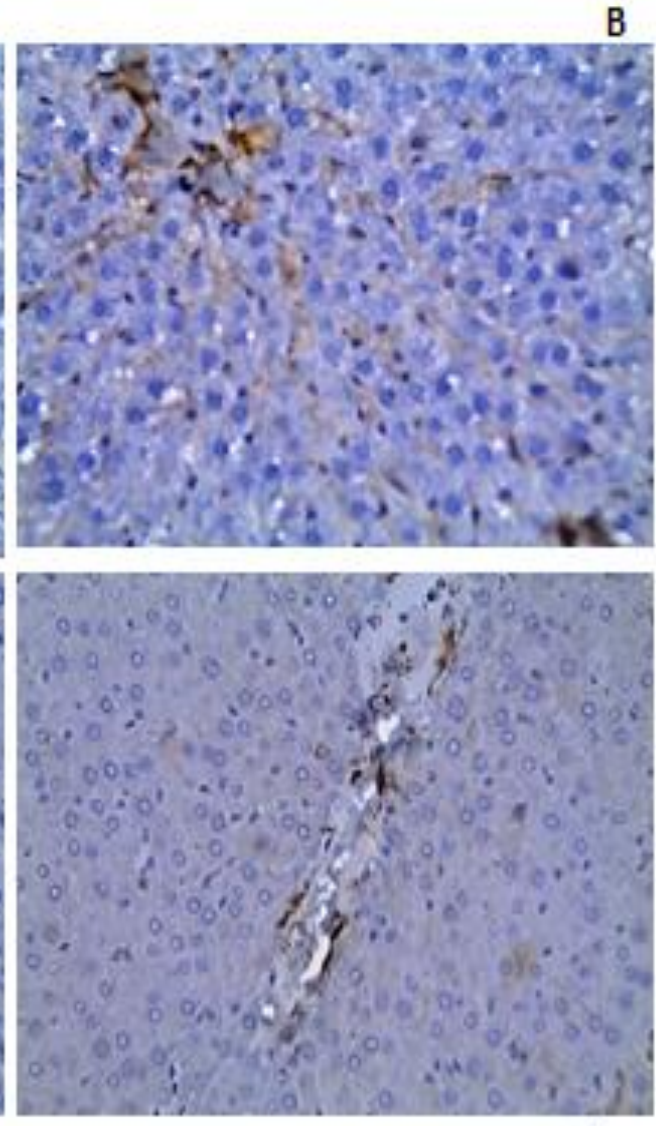

D

Figure 2: Photomicrographs of liver sections were immunostained with $\alpha$-SMA. A: Group (1) (control vehicle) shows few cells were stained with $\alpha$-SMA within the lobule. B: Group (2) $\left(\mathrm{CCl}_{4}\right.$ treated rats; $1 \mathrm{~mL}$ of CCl4/corn oil (1:1, $\mathrm{v} / \mathrm{v}) / \mathrm{kg}$, i.p. injection twice weekly for 12 weeks). It shows numerous $\alpha$-SMA positive cells around portal triad and central vein. C: Group (3) (CCl4+curcumin 4w; $1 \mathrm{~mL}$ of CCl4/corn oil (1:1, v/v)/kg, i.p. injection twice weekly for 12 weeks $)+$ curcumin $\left(300 \mathrm{mg} / \mathrm{kg}\right.$, three times/week, for 4 weeks after withdrawal of $\left.\mathrm{CCl}_{4}\right)$. It shows small number of $\alpha$-SMA positive cells around portal triad and central vein indicated less fibrosis and improvement by treatment. D: Group (4) (CCl4+curcumin 6w; $1 \mathrm{~mL}$ of $\mathrm{CCl} 4 /$ corn oil $(1: 1, \mathrm{v} / \mathrm{v}) / \mathrm{kg}$, i.p. injection twice weekly for 12 weeks $)+$ curcumin $\left(300 \mathrm{mg} / \mathrm{kg}\right.$, three times/week, for 6 weeks during $\mathrm{CCl}_{4}$ administration. It shows few $\alpha$-SMA positive cells around portal triad and central vein are present.

\subsection{Effect of curcumin on antioxidant enzyme activities}

Table (1) shows that curcumin induced alteration of antioxidant enzymes in liver against $\mathrm{CCl}_{4} \cdot \mathrm{CCl}_{4}$ administration alone significantly decreased SOD and GPx activities by $60.3 \%$ and $62 \%(\mathrm{P}<0.001)$ respectively as compared to control vehicle group, whereas treatment with curcumin in group (3) significantly protected the liver and prevented the decrease in SOD \& GPx 
activities by $301 \%$ and $199.3 \% \quad(\mathrm{P}<0.001)$ respectively compared to $\mathrm{CCl}_{4}$ treated group. Treatment with curcumin after $\mathrm{CCl}_{4}$ withdrawal in group (3) showed much increase in SOD \& GPx activities by $16.8 \%$ and $47.34 \%$ respectively compared to group (4) in which curcumin was given simultaneously with $\mathrm{CCl}_{4}$. to $\mathrm{CCl}_{4}$ group. The hepatoprotective effect of curcumin is more observed in group (3) after $\mathrm{CCl}_{4}$ withdrawal than in group (4) (Fig. 3 and Tab. 1).

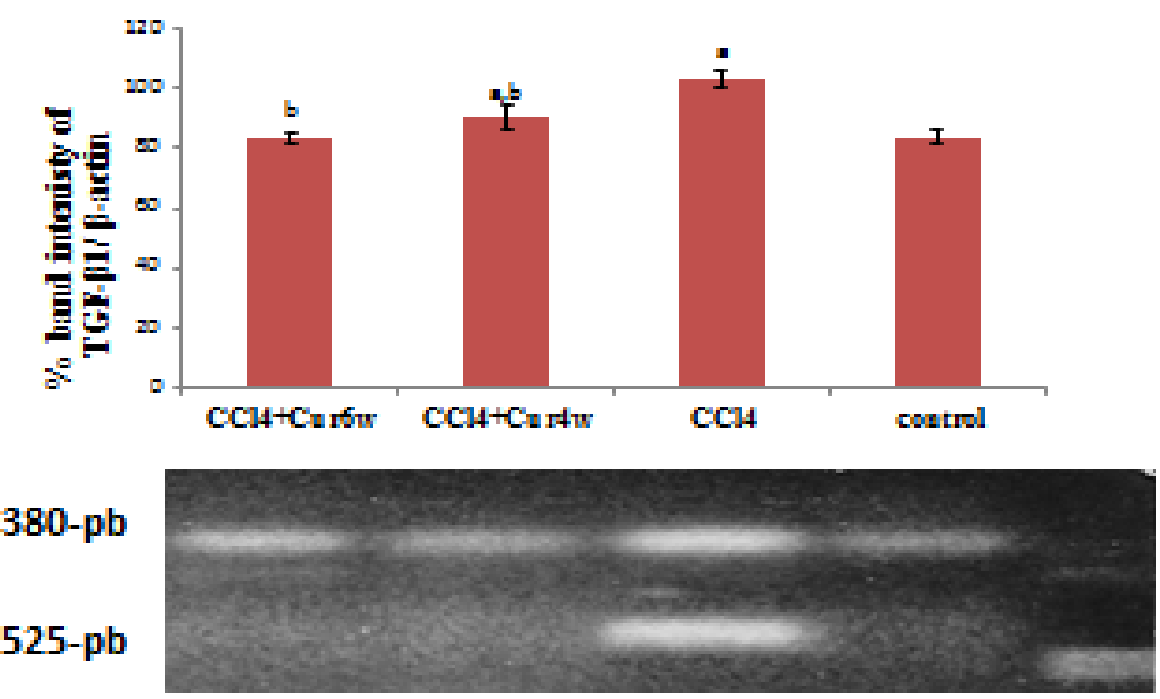

\section{$\beta$-actin}

TGF- $\beta 1$

Figure 3: Gene expression of TGF- $\beta 1$ in liver tissue determined by RT-PCR. Control Group (I), Group (2) $\mathrm{CCl}_{4}$, Group (3) $\left(\mathrm{CCl}_{4}+\right.$ Curcumin $4 \mathrm{w}$ administered after withdrawal of $\left.\mathrm{CCl}_{4}\right)$ and Group (4) $\mathrm{CCl}_{4}+$ curcumin $6 \mathrm{w}$ administered after 6 weeks of $\mathrm{CCl}_{4}$ treatment for successive 6 weeks. $\beta$-Actin was used as control. Band intensities were calculated as the ratio of TGF- $\beta 1 / \beta$-actin. Each bar represents the mean value \pm SD of six rats; ' $a$ ' means significantly different from control, ' $\mathbf{b}$ ' means significantly different from the $\mathrm{CCl}_{4}$ group. $\mathrm{P}<0.05$ was set as significant.

\subsection{Effect of curcumin on plasma level of} TGF- $\beta 1$ and its gene expression (Fig. 3 and Tab. 1)

The most profibrogenic factor is the cytokine TGF- $\beta$. Therefore; we aimed to investigate if the antifibrotic effects of curcumin were associated with diminishing this mediator. Figure (3) and Table (1) show that gene expression and plasma level of TGF- $\beta 1$ in $\mathrm{CCl}_{4}$ group were increased by $23.5 \%(\mathrm{P}<0.001)$ and $120.9 \% \quad(\mathrm{P}<0.001)$ respectively compared to control group. Plasma level of TGF- $\beta 1$ and its gene expression were reduced with curcumin administration in group (3) by $52.34 \%(\mathrm{P}<0.001)$ and $12 \%(\mathrm{P}<0.02)$ respectively compared to $\mathrm{CCl}_{4}$ group. In group (4) curcumin reduced plasma level of TGF- $\beta 1$ by $15.27 \%(\mathrm{P}<0.01)$ and its gene expression by $19.33 \%(\mathrm{P}<0.001)$ compared

\section{Discussion}

In the present study the model of liver fibrosis experimentally-induced by administration of $\mathrm{CCI}_{4}$ in rats for 12 weeks was demonstrated. $\mathrm{CCl}_{4}$-induced fibrosis in rats shares many characteristics with human fibrosis; thus, it is an adequate model of human fibrosis [13].

$\mathrm{CCl}_{4}$ is metabolized by cytochrome $\mathrm{P} 4502 \mathrm{El}$ to form a reactive trichloromethyl radical $\left(\mathrm{CCl}_{3}{ }^{\circ}\right)$ and a trichloromethyl peroxyl radical $\left(\mathrm{CCl}_{3} \mathrm{O}_{2}{ }^{\circ}\right)$. Both radicals bind to DNA, lipids, proteins or carbohydrates, leading to lipid peroxidation, cell necrosis, and excessive deposition of collagen in liver. Kupffer cells are activated by free radicals and produce proinflammatory mediators, resulting in the triggering of an inflammatory cascade [11]. 
In the present study, the hepatotoxicity of $\mathrm{CC}_{4}$ in rats was confirmed by a significant elevation of AST, ALT, and total bilirubin. In addition, $\mathrm{CC}_{4}$ intoxication produced a significant reduction in plasma total protein level. This may be due to release of these enzymes from the cytoplasm into the blood rapidly after cellular damage and a reduction in hepatic protein synthesis. These effects were further confirmed by histopathological observations of liver, where variable forms of hepatocytes degeneration, fatty changes, apoptosis and necrosis were observed [13].

Our results showed a significant increase in hydroxyproline level in $\mathrm{CCl} 4$ treated rats. These results were in accordance with other investigators [4]. In addition, the $\mathrm{CCl}_{4}$-elevated levels of hydroxyproline were significantly reduced by oral curcumin administration in both groups $3 \& 4$. The antifibrotic effect of curcumin was more observed after $\mathrm{CCl}_{4}$ withdrawal (group $3)$.

Hydroxyproline is a sensitive marker that increases significantly during liver fibrosis. Its increase reflects an increase in the de novo synthesis of liver collagen. Its determination is a good method to quantify fibrosis and to evaluate the effectiveness of antifibrotic agents [13].

In the present study, many $\alpha$-SMA positive cells were detected in $\mathrm{CCl}_{4}$ treated group; while curcumin treated groups showed few activated cells. HSCs are primary target cells for inflammatory stimuli in the injured liver. Once activated, HSCs is transformed into $\alpha$-SMA positive myofibroblast-like cells, which are responsible for collagen hypersecretion during hepatic fibrogenesis [4].

In fibrogenesis, the normal ECM is converted to fibrillar and contractile ECM. Mohamed et al [4] demonstrated that hepatic recovery from fibrosis involves the destruction of fibrous bands by matrix metalloproteinases (MMPs). MMP-2 and MMP-9 are capable of degrading basement membrane proteins like gelatin, collagen IV, collagen $\mathrm{V}$, elastin, and fibronectin.

It has been reported that curcumin regulates the expression and activity of MMP-2 and MMP-9 in human bronchial epithelial cells and during prevention and healing of indomethacin-induced gastric ulcer. Therefore, the antifibrotic effect observed by curcumin may be explained through the modulation of MMPs [14].

In addition, curcumin exerts several antioxidative, antiinflammatory, antifibrogenic and antiproliferative effects in HSCs. Curcumin inhibited hepatic fibrosis in a rodent model by reducing oxidative stress and inhibiting HSC activation and induces apoptosis [15].

Our results revealed that TGF- $\beta 1$ was significantly elevated by chronic administration of $\mathrm{CCl}_{4}$ as compared to control vehicle group. The increase in the profibrotic cytokine, TGF- $\beta 1$, mostly from Kupffer cells, stimulates type IV collagen and fibrinogen which in turn activates HSCs [16].

Inflammation is associated with hepatic fibrogenesis. $\mathrm{CCl}_{4}$ metabolites attack hepatocytes and cause necrosis of parenchymal cells and activate proinflammatory mediators TNF- $\alpha$, IFN$\gamma$ and IL-6. These mediators stimulate the hepatic fibrosis and production of ECM by activated HSC and fibrogenic TGF- $\beta 1$ from Kupffer cells [17].

The anti-inflammatory effect of curcumin was apparent in the current study. Curcumin administration after $\mathrm{CCl}_{4}$ withdrawal significantly reduced TGF- $\beta 1$ level and reversed it to its normal level, while concomitant administration with $\mathrm{CCl}_{4}$ partially but significantly reduced TGF- $\beta 1$ level compared to $\mathrm{CCl}_{4}$ group.

The anti-inflammatory effect of curcumin may be mediated through inhibition of I kappa $\beta$ kinase activity leading to suppression of NF- $\kappa \mathrm{B}$ activation. The inhibition of NF- $\kappa \mathrm{B}$, TGF- $\beta$, and mitogen-activated protein kinase pathway has an important role in the antiinflammatory effect of curcumin [18].

The current study demonstrated that $\mathrm{CCl}_{4}$ significantly reduced the antioxidant activity of both SOD and $\mathrm{GP}_{\mathrm{X}}$ in liver. Oxidative stress is a major cause of liver damage. Bioactivation of $\mathrm{CCl}_{4}$ to $\mathrm{CCl} 3 \mathrm{OO}$ - radicals by cytochrome $\mathrm{P} 450$ increase oxidative stress. ROS are highly reactive and covalently bind to cellular macromolecules with preference for fatty acids from membrane 
phospholipids leading to lipid peroxidation, damage of membrane enzymes, and disrupt cell energy generation and protein synthesis [19].

Moreover, ROS produced are involved in necrosis and apoptosis of hepatocytes and HSC activation during liver fibrogenesis [17].

The antioxidant effect of curcumin was confirmed in the present study; curcumin significantly modulated the activities of SOD and GPx after $\mathrm{CCl}_{4}$ withdrawal. These results were in accordance with Nabavi [20], who found that the antioxidant activity of curcumin plays an important role in its therapeutic action in nonalcoholic fatty liver disease and the preventive role of curcumin against fibrosis may be due to its antioxidant action. In addition, curcumin inhibits the attraction of neutrophil granulocytes and myofibroblasts.

Curcumin supplementation improves liver function by decreasing superoxide production and by suppressing pro-inflammatory mediators and activating anti-inflammatory signaling pathways [16]. Curcumin elevates the level of cellular GSH and induces de novo synthesis of GSH in HSC by stimulating the activity and gene expression of glutamatecysteine ligase, a key rate-limiting enzyme in GSH synthesis. These effects may recommend curcumin as a hepatoprotective agent [21].

In conclusion, our results indicated that curcumin was effective in reversing hepatic fibrosis after $\mathrm{CCl}_{4}$ withdrawal than during concomitant administration. It reduces oxidative stress, serum markers of hepatic injury and possesses antifibrogenic and fibrolitic effects. In addition, its ability to down-regulate TGF- $\beta 1$. Therefore, curcumin may be considered an effective therapeutic antifibrotic agent for the treatment of hepatic fibrosis by suppressing proinflammatory molecules and oxidative stress.

\section{Acknowledgement}

The study is financially supported by faculty of pharmacy, Tanta University Egypt.

\section{References}

[1] Rukkumani, R.; Aruna, K.; Varma, P.S.; Menon, V.P.; Curcumin influences hepatic expression patterns of matrix metalloproteinases in liver toxicity. Ital $\mathrm{J}$ Biochem, 2004; 53(2):61- 66. PMID: $\underline{15646009}$

[2] Galicia-Moreno, M.; Rodríguez-Rivera, A.; Reyes-Gordillo, K.; Segovia, J.; Shibayama, M.; Tsutsumi, V.; Vergara, P.; Moreno, M.G.; Fernández-Martínez, E.; PérezÁlvarez, V.M.; Muriel, P.; Trolox downregulates transforming growth factor- $\beta$ and prevents experimental cirrhosis. Basic Clin Pharm Toxicol, 2008; 103: 476-481. doi: 10.1111/j.1742-7843.2008.00324.x.

[3] Gupta, S.C.; Kismali, G.; Aggarwal, B.B.; Curcumin a component of turmeric: from farm to pharmacy. Bio Factors, 2013; 39(1):2-13. doi: 10.1002/biof.1079

[4] Mohamed, S.H.; Elbastawisy, Y.M.; Efficacy of curcumin in protecting the rat liver from CCl4-induced injury and fibrogenesis, Histological and immunohistochemical study. Life Science J, 2013; 10 (1): 28242835. (ISSN: 1097-8135).

[5] Lowry, O.H.; Rosenbrough, N.J.; Farr, A.L.; Randall, R.J.; Protein measurement with the Folin- Phenol Reagent. J Biol Chem, 1951; 193:265-275.

http://www.jbc.org/content/193/1/265

[6] Bergman, I.; Loxley, R.; Two improved and simplified methods for the spectrophotometric determination of hydroxyproline. Anal Chem, 1963; 35 (12): 1961-1965. doi: 10.1021/ac60205a053

[7] Paglia, D.E.; Valentine, W.N.; Studies on the quantitative and qualitative characterization of erythrocyte glutathione peroxidase. J Lab Clin Med, 1967; 70: 158 - 169. PMID: $\underline{6066618}$

[8] Nishikimi, M., Roa, N.A.; Yogi, K.; Measurement of superoxide dismutase. Biochem Biophys Res Common, 1972; 46: 849-854.

[9] Reyes-Gordilloa, K.; Segoviab, J.; Shibayamac, M., Tsutsumic, V.; Vergarab, P.; Morenoa, M.G.; Murie, P.; Curcumin 
prevents and reverses cirrhosis induced by bile duct obstruction or $\mathrm{CCl} 4$ in rats: role of TGF-b modulation and oxidative stress. Fundamental \& Clinical Pharmacology, 2008; 22: 417-427. doi: 10.1111/j.14728206.2008.00611.x.

[10] Li, L.; Hu, Z.; Li, W.; Hu, M.; Ran, J.; Chen, P.; Sun, Q.; Establishment of a standardized liver fibrosis model with different pathological stages in rats. Gastroenterology Research and Practice, 2012; 2012: 560345, doi:10.1155/2012/560345.

[11] Lee, G.; Jeong, W.; Jeong, D.; Do, S.; Kim, T.; Jeong, K.; Diagnostic evaluation of carbon tetrachloride-induced rat hepatic cirrhosis model. Anticancer Research, 2005; 25: 1029-1038. doi: $\underline{0250-7005 / 2005}$ $\$ 2.00+.40$

[12] Landau, S.; Everitt, B.S.; Handbook of Statistical Analyses using SPSS, Chapman \& Hall/CRC Press LLC, USA, 2004.

[13] Fu, Y.; Zheng, S.; Lin, J.; Ryerse, J.; Chen, A.; Curcumin protects the rat liver from ccl4-caused injury and fibrogenesis by attenuating oxidative stress and suppressing inflammation. Mol Pharmacol, 2008; 73(2): 399-409. doi: 10.1124/mol.107.039818

[14] Zheng, S.; Chen, A.; Curcumin suppresses the expression of extracellular matrix genes in activated hepatic stellate cells by inhibiting gene expression of connective tissue growth factor. Am J Physiol Gastrointest Liver Physiol, 2006; 290: G883-G893. doi: 10.1038\%2Fsj.bjp.0707542

[15] Connell, M.; Rushworth, S.A.; Commentary Curcumin: potential for hepatic fibrosis therapy? BJP, 2008; 153: 403-405. doi:10.1038\%2Fsj.bjp.0707580
[16] Armendariz-Borunda, J.; Katai, H.; Jones, C.M.; Seyer, J.M.; Kang, A.H.; Raghow, R.; Transforming growth factor beta gene expression is transiently enhanced at a critical stage during liver regeneration after $\mathrm{CCl}_{4}$ treatment. Lab Invest, 1993; 69(3): 283-94. PMID: 8377471

[17] Murie, P.; Role of free radicals in liver diseases. Hepatol Int, 2009; 3(4): 526-536. doi: 10.1007\%2Fs 12072-009-9158-6

[18] Yao, Q.Y.; Xu, B.L.; Wang, J.Y.; Liu, H.C.; Zhang, S.C.; Tu, C.T.; Inhibition by curcumin of multiple sites of the transforming growth factor-betal signalling pathway ameliorates the progression of liver fibrosis induced by carbon tetrachloride in rats. BMC Complement Altern Med, 2012; 16 (12): 156-167. doi:10.1186/1472-6882-12-156

[19] Xie, Q.; Guo, F.F.; Zhou, W.; Protective effects of cassia seed ethanol extract against carbon tetrachloride-induced liver injury in mice. Acta Biochimica Polonica, 2012; 59 (2): 265-270. PMID: 22693685

[20] Nabavi, S.F.; Daglia, M.; Moghaddam, A.H.; Habtemariam, S.; Nabavi, S.M.; Curcumin and Liver Disease: from Chemistry to Medicine. Comprehensive Reviews in Food Science and Food Safety, 2014; 13 (1):62-77. doi: 10.1111/15414337.12047

[21] Zheng, S. Yumei, F.; Chen, A.; De novo synthesis of glutathione is a prerequisite for curcumin to inhibit hepatic stellate cell (HSC) activation. Free Radic Biol Med, 2007; 43: 444-453. $\quad$ doi: $10.1016 \% 2 \mathrm{Fj}$. freeradbiomed.2007.04.016 